\title{
Editorial
}

\section{Pain - Skin Deep at Times?}

Howard S. Smith, MD

$\mathrm{n}$ recent years it has become apparent that the skin is not merely a static organ with barrier functions. Skin is an extremely dynamic organ that participates in multiple homeostatic and other functions. Furthermore, there is a growing appreciation of the skin's key role in contributing to certain persistent nociceptive processes (1). Petersen and colleagues (2) have suggested a contributing nociceptive role of skin in certain patients with postherpetic neuralgia since surgical excision of painful skin resulted in immediate reduction in pain and analgesic use.

Skin incision alone appears sufficient to result in primary mechanical, thermal, or chemical hyperalgesia. However, incised deep tissue is necessary for the development of guarding pain and increased spontaneous activity of dorsal horn neurons $(3,4)$. Kang and Brennan (4) demonstrated that one day after a skin incision, C-fibers located within $2 \mathrm{~mm}$ from the incision exhibited greater chemosensitivity to $\mathrm{pH} 6.0$ lactic acid compared to control.

Wei et al (5) using a tibia fracture rat model found that fracture chronically increased the expression of endothelial and keratinocyte neurokinin-1 (NK-1) receptors in the injured limb. Also, subcutaneous and intravenous substance P-evoked extravasation responses are augmented in the ipsilateral hindlimb post-fracture (5). Substance $\mathrm{P}$, activating upregulated NK-1 receptors in the injured limb, may promote keratinocyte proliferation (5).

In epidermal keratinocytes nerve growth factor (NGF) production facilitates neuropeptide release (6). After the release of neuropeptides by a nociceptive stimulus, an upregulation of the expression of NGF and an increase in NGF secretion from keratinocytes is induced (7). Interleukin-1B (IL-1B) may directly activate sensory neurons and also upregulates nerve growth factor (NGF) expression in keratinocytes (8). Anti-NGF therapy inhibits hyperalgesia (8). NGF rap- idly increases membrane expression of TRPV1 heatgated ion channels (9). NGF may lower the activation threshold induction of pain $(9,10)$. Kawamata et al suggested a close interaction between TRPV1 and ETA (11) during ET-1-induced thermal hyperalgesia. Activation of the ETA-protein kinase $C$ pathway may result in sensitization of TRPV1 activity which is needed for ET-1-induced thermal hyperalgesia (11).

\section{Keratinocytes and Nociception}

Keratinocytes may be intimately involved in the modulation of certain nociceptive processes via multiple mechanisms. It is possible that in certain painful conditions keratinocytes may contribute to modulation of nociceptive processes by an increase or decrease in the number and/or function of specific ion channels (e.g. sodium channels [NaV], transient receptor potential vanilloid [TRPV] ion channels) as well as by an increase or decrease in the amount of specific mediator release from keratinocytes (e.g. opioids, prostaglandins, adenosine triphosphate [ATP]) (Fig. 1).

The antinociceptive effects of the $C B(2)$ receptorselective agonist AM1241 were prevented in rats when naloxone or antiserum to beta-endorphin was injected

From: Albany Medical College Department of Anesthesiology, Albany, NY.

Dr. Smith is Editor-in-Chief of the Pain Physician journal and Associate Professor and Academic Director of Pain Management for Albany Medical College Department of Anesthesiology, Albany, NY.

Address correspondence: Howard S. Smith, MD Associate Professor \& Academic Director of Pain Management Albany Medical College Department of Anesthesiology 47 New Scotland Avenue; MC-131 Albany, New York 12208 E-mail: smithh@mail.amc.edu 


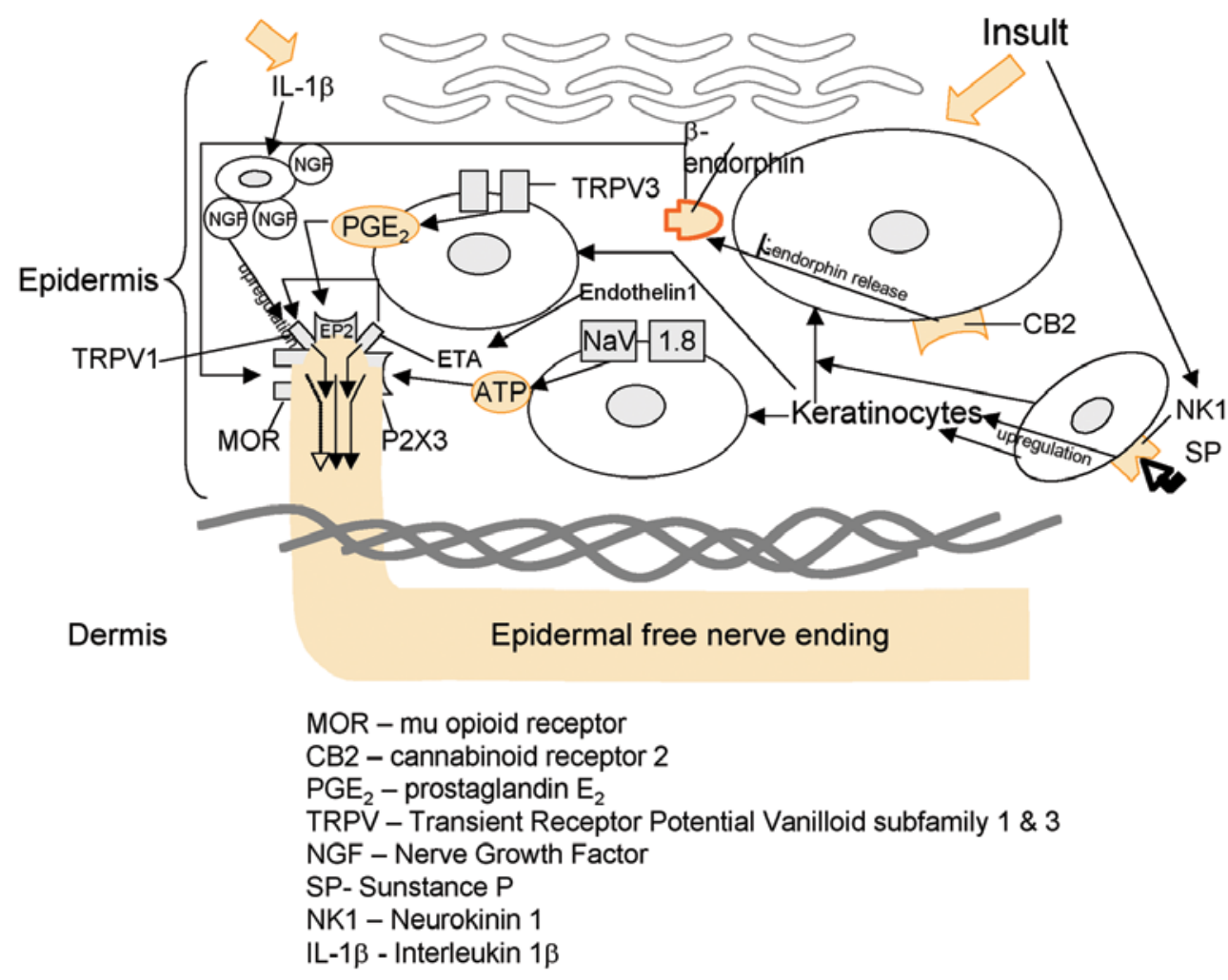

Fig. 1. Schematic of multiple potential mechanisms whereby keratinocytes may modulate nociceptive processes in the skin.

in the hindpaw where the noxious thermal stimulus was applied, suggesting that beta-endorphin is necessary for $\mathrm{CB}(2)$ receptor-mediated antinociception (12). However, AM1241 did not inhibit nociception in mu-opioid receptor-deficient mice (12). Hindpaw injection of beta-endorphin was sufficient to produce antinociception. AM1241 stimulated beta-endorphin release from rat skin tissue and from cultured human keratinocytes (12). This stimulation was prevented by AM630, a CB(2) cannabinoid receptor-selective antagonist and was not observed in skin from $\mathrm{CB}(2)$ cannabinoid receptor-deficient mice (12). These data suggest that $\mathrm{CB}(2)$ receptor activation stimulates release from keratinocytes of beta-endorphin, which acts at local neuronal mu-opioid receptors to inhibit nociception (12). Furthermore, $\mathrm{CB}(2)$ immunolabeling was detected on beta-endorphin-containing keratinocytes in stratum granulosum throughout the epidermis of the hindpaw (12).

Keratinocytes appear to be able to act as thermal receptors via TRPV1 (13). The study of Wilder-Smith et al (13) suggests that in human painful distal small nerve fiber neuropathies, epidermal TRPV1 expression is mainly in keratinocytes. Huang and colleagues (14) generated and characterized transgenic mice that overexpress TRPV3 in epidermal keratinocytes under the control of the keratin 14 promoter. Compared with wild-type controls, keratinocytes overexpressing TRPV3 exhibited larger currents as well as augmented prostaglandin $E(2)(P G E(2))$ release in response to 2 TRPV3 agonists, 2-aminoethoxydiphenyl borate (2APB), and heat. Upon selective pharmacological inhibition of TRPV1 with JNJ-17203212 (corrected), however, the keratinocyte-specific TRPV3 transgenic mice showed increased escape responses to noxious heat relative to their wild-type littermates (14). Coadministration of the cyclooxygenase inhibitor, ibuprofen, with the TRPV1 antagonist decreased inflammatory thermal hyperalgesia in transgenic but not wild-type animals (14). The results of Huang et al (14) reveal a mechanism for keratinocyte participation in thermal 
pain transduction through keratinocyte TRPV3 ion channels and the intercellular messenger PGE(2).

Zhao et al (15) examined whether keratinocytes may contribute to human pain states, by analyzing sodium channel expression in human skin biopsies from subjects with complex regional pain syndrome Type 1 (CRPS) and post-herpetic neuralgia (PHN) using immunohistochemistry. Control skin exhibited immunolabeling for $\mathrm{Na}(\mathrm{v}) 1.5, \mathrm{Na}(\mathrm{v}) 1.6$, and $\mathrm{Na}$ (v) 1.7 (15). In contrast, painful skin from CRPS and PHN subjects displayed $\mathrm{Na}(\mathrm{v}) 1.1, \mathrm{Na}(\mathrm{v}) 1.2$, and $\mathrm{Na}(\mathrm{v}) 1.8$ immunolabeling, in addition to substantially increased signal for $\mathrm{Na}(\mathrm{v}) 1.5, \mathrm{Na}$ (v)1.6, $\mathrm{Na}(\mathrm{v}) 1.7$. These observations lead
Zhao and colleagues (15) to propose that pathological increases in keratinocyte sodium channel expression may contribute to pain by increasing epidermal ATP release, resulting in excessive activation of $P 2 X$ receptors on primary sensory axons. Consistent with this hypothesis, animal models of neuropathic pain exhibit increases in subcutaneous ATP release and activity of primary sensory neurons; also peripheral administration of $\mathrm{P} 2 \mathrm{X}$ antagonists have been shown to reduce neuropathic pain in humans (15). Thus, it appears that skin possesses an extensive and complex array of nociceptive modulating systems that may cause pain in certain circumstances.

\section{References}

1. Albrecht PJ, Hines S, Eisenberg E, Pud D, Finlay DR, Connolly MK, Paré M, Davar G, Rice FL. Pathologic alterations of cutaneous innervation and vasculature in affected limbs from patients with complex regional pain syndrome. Pain 2006; 120:244-266.

2. Petersen KL, Rice FL, Suess F, Berro M, Rowbotham MC. Relief of post-herpetic neuralgia by surgical removal of painful skin. Pain 2002; 98:119-126.

3. Xu J, Brennan TJ. Comparison of skin incision vs. skin plus deep tissue incision on ongoing pain and spontaneous activity in dorsal horn neurons. Pain 2009; In Press.

4. Kang S, Brennan TJ. Chemosensitivity and mechanosensitivity of nociceptors from incised rat hindpaw skin. Anesthesiology 2009; 111:155-164.

5. Wei T, Li W-w, Guo T-Z, Zhao R, Wang L, Clark JD, Oaklander AL, Schmelz M, Kingery WS. Post-junctional facilitation of substance $P$ signaling in a tibia fracture rate model of complex regional pain syndrome type 1. Pain 2009; In Press.

6. Ständer S, Schneider SW, Weishaupt C, Luger TA, Misery L. Putative neuronal mechanisms of sensitive skin. Exp Der- matology 2009; 18:417-423.

7. Dallos A, Kiss M, Polyánka H, Dobozy A, Kemény L, Husz S. Effects of the neuropeptides substance $P$, calcitonin generelated peptide, vasoactive intestinal polypeptide and galanin on the production of nerve growth factor and inflammatory cytokines in cultured human keratinocytes. Neuropeptides 2006; 40:251-263.

8. Li W-w, Sabsovich I, Gui T-Z, Xhao R, Kingery WS, Clark JD. The role of enhanced cutaneous IL-1 signaling in a rat tibia fracture model of complex regional pain syndrome. Pain 2009; In Press.

9. Zhang X, Huang J, McNaughton PA. NGF rapidly increases membrane expression of TRPV 1 heat-gated ion channels. EMBO / 2005: 24:4211-4223.

10. Pei L, Lin CY, Dai JP, Yin GF. Facial pain indices the alteration of transient receptor potential vanilloid receptor 1 expression in rat trigeminal ganglion. Neurosci Bull 2007; 23: 92-100.

11. Kawamata T, Ji W, Yamamoto J, Niiyama Y, Furuse S, Namiki A. Contribution of transient receptor potential vanilloid subfamily 1 to endothelin-1-induced thermal hyperalgesia. Neuroscience
2008; 154:1067-1076.

12. Ibrahim MM, Porreca F, Lai J, Albrecht PJ, Rice FL, Khodorova A, Davar G, Makriyannis A, Vanderah TW, Mata HP, Malan TP Jr. CB2 cannabinoid receptor activation produces antinociception by stimulating peripheral release of endogenous opioids. Proc Natl Acad Sci U S A 2005; 102:3093-3098.

13. Wilder-Smith EP, Ong WY, Guo Y, Chow AW. Epidermal transient receptor potential vanilloid 1 in idiopathic small nerve fibre disease, diabetic neuropathy and healthy human subjects. Histopathology 2007; 51:674-680.

14. Huang SM, Lee H, Chung MK, Park U, Yu YY, Bradshaw HB, Coulombe PA, Walker JM, Caterina MJ. Overexpressed transient receptor potential vanilloid 3 ion channels in skin keratinocytes modulate pain sensitivity via prostaglandin E2. J Neurosci 2008; 28:13727-13737.

15. Zhao P, Barr TP, Hou Q, Dib-Hajj SD, Black JA, Albrecht PJ, Petersen K, Eisenberg E, Wymer JP, Rice FL, Waxman SG. Voltage-gated sodium channel expression in rat and human epidermal keratinocytes: evidence for a role in pain. Pain 2008; 139:90-105. 
